\title{
Restricting access to the NHS for undocumented migrants is bad policy at high cost
}

\author{
Charging migrants for access to health services will not reduce strain on the NHS, say Lilana Keith \\ and Ewout van Ginneken
}

\author{
Lilana Keith interim programmes director, Platform for International Cooperation on Undocumented \\ Migrants, Brussels, Belgium, Ewout Van Ginneken senior researcher, Berlin University of Technology, \\ Berlin, Germany
}

The shocking loss of life among migrants crossing the Mediterranean and the UK government's refusal to contribute to European search and rescue efforts despite public outcry have thrown into sharp focus the dehumanisation of migrants through negative political rhetoric and policies. Migrants' right to life is also challenged by limited access to healthcare, particularly in the United Kingdom, where the first of several measures restricting access to NHS services for migrants, in a supposed "crackdown on health tourism," came into force on 6 April 2015. ${ }^{1}$ But what are the real effects of such measures?

\section{Immigration health charge}

The new policy imposes an up-front surcharge to guarantee access to NHS hospital care for people from outside the European Economic Area when they submit an application to work, study, or visit their families in the UK for a period of longer than six months or when they are already in the UK applying to extend their visas. ${ }^{2}$ The surcharge is $£ 200$ ( $€ 275$; $\$ 310$ ) a year ( $£ 150$ for students) for the maximum period of time that could be granted-for example, $£ 400$ for a two year visa (in addition to the application fee). Those who cannot pay will automatically have their application rejected.

Some applicants do not need to pay the surcharge, such as asylum seekers and victims of human trafficking. However, not all vulnerable groups of migrants are protected from these charges. There are two groups of concern. The first is people residing regularly in the UK but in poverty; they may become irregular migrants simply because they cannot afford to pay these charges when they apply to extend their leave. The second are undocumented migrants and their families who are trying to regularise their residence. The majority of the estimated 618 000 undocumented migrants in the UK did not enter Europe irregularly. Instead they are people who entered the country on a work or spousal visa that was linked to one particular job or personal relationship and was rendered automatically invalid or impossible to extend when that relationship broke down. This is often due to exploitation at work or domestic violence. Administrative delays, fees, and requirements are other common reasons for people not being able to extend their leave and becoming "undocumented."

The NHS has already been implicated; any immigration application from a person who has more than $£ 1000$ of debt for NHS services is automatically rejected. The surcharge adds another barrier that will push people into irregularity and prevent some undocumented migrants with a right to reside in the UK from being able to regularise their residence.

This policy alone makes the UK an outlier in Europe. No other EU country has such a structural link between immigration applications and access to health services. Another measure that has been suggested, but postponed subject to further public consultation, is to charge undocumented migrants for emergency and primary services. These services are currently provided free of charge to all people regardless of residence status, while other hospital care must be paid for. ${ }^{34}$ This is already a narrower range of services than provided by some other EU countries with significant migrant populations, such as France $\downarrow$. If the additional measures are approved the UK's health services will be among the least accessible in Europe.

\section{Shortsighted and misleading}

The UK government wants the public to believe that the changes being proposed will make the country less appealing to undocumented migrants and will save taxpayers' money. This view is shortsighted and misleading.

Are undocumented migrants "health tourists"? In a survey of migrants visiting Doctors of the World UK's clinic in Bethnal Green, London, only $2.6 \%$ of respondents cited health problems as a reason for migration, far behind economic survival (39.6\%) and political, religious, ethnic, or sexual orientation $(23.4 \%){ }^{5}$ This is in line with findings from other European countries. The survey also found that $82.7 \%$ of respondents did not have access 
to the NHS due to legal, administrative, or language barriers and fear of deportation. On average respondents had been living in the UK for 6.5 years.

The estimated 618000 undocumented migrants living in the UK contribute to the economy through their employment, purchase goods and services (including VAT), and may even pay or have paid income tax. They are not free riders in the NHS but contributors. Not providing them with coverage is unfair as well as contrary to their rights as human beings.

Would it save public funds? Little is known about the cost of giving migrants full access to the health system compared with partial or no access. But a few considerations are relevant. Firstly, denying access to undocumented migrants may end up costing the NHS more in the long run. Emergency services, which must be provided at the point of need, are exponentially more expensive than preventive or planned care. Furthermore, the NHS can rarely recoup these costs from patients who lack the means to pay. Secondly, not having access to preventive services may lead to outbreaks, with subsequent costs to the health system and wider society. Thirdly, evidence shows that undocumented migrants are healthier, cost less to cover, and use services they are entitled to less than nationals. ${ }^{67}$ Lastly, restricting access to services based on residence status requires complex administration, itself a major burden on the NHS. Health professionals have also expressed concern over being expected to act against their professional ethics and act as border guards. ${ }^{8}$

Some countries and regions across Europe have chosen to provide preventive and curative care to all their residents. Sweden has found that providing a range of health services for undocumented migrants is costing much less than they had predicted. ${ }^{9}$ At the same time, Spain, which recently restricted access to care for undocumented migrants, is now making a U-turn. Until September 2012 undocumented migrants in Spain had almost the same access to health services as other residents. The policy change allowed them access only to emergency services and care for pregnant women and children. However, only one regional government fully implemented the national policy, and the minister of health recently announced that undocumented migrants would now be entitled to primary care again, citing pressure on emergency services. ${ }^{10}$

\section{Negative knock-on effects}

The UK government is wrong to assume that charging migrants for access to health services will strongly reduce the strain on NHS resources. The restrictions already imposed are disproportionate to their stated goals, as they have several negative knock-on effects on public health, healthcare professionals, medical ethics and human rights, and the administration and finances of the healthcare system, as well as causing direct harm to the health and wellbeing of vulnerable people. Rather than holding a public consultation on extending these charges to emergency and primary care, as the freshly elected Conservative government plans to do, the evidence indicates that the opposite approach would serve the UK and its NHS better. They should explore ways to provide non-discriminatory access to the NHS for all.

1 Department of Health. Visitor and migrant NHS cost recovery programme. Implementation plan 2014-16. Jul 14. www.gov.uk/government/uploads/system/uploads/attachment_data/ plan 2014-16.Jul 14. www.gov.uk/government/uploads/sys
file/329789/NHS_Implentatation_Plan_Phase_3.PDF.

2 UK Draft Statutory Instruments. The immigration (health charge) order 2015. www. legislation.gov.uk/ukdsi/2015/9780111128473.

3 Coram Children's Legal Centre. Access to primary healthcare for migrant children, young people and families. www.childrenslegalcentre.com/userfiles/Access\%20to\%20primary\% 20healthcare\%20for\%20migrant\%20children_Final.pdf.

4 Coram Children's Legal Centre. Access to secondary healthcare for migrant children, young people and families. www.childrenslegalcentre.com/userfiles/Access $\% 20$ to\% 20 secondary\%20healthcare\%20for\%20migrant\%20children_Final\%282\%29.pdf.

5 Chauvin P, Simonnot N, Vanbiervliet F, Vicart M, Vuillermoz C. Access to healthcare for people facing multiple vulnerabilities in health in 26 cities across 11 countries. Report on the social and medical data gathered in 2014 in nine European countries, Turkey and Canada. May 2015. https://mdmeuroblog.files.wordpress.com/2014/05/mdm-intl-networkfull-report-11-countries-18th-may-2015.pdf.

6 Fuentes FJM, Callejo MB. Immigration and the welfare state in Spain. 2011. http://www. academia.edu/401847/Immigration_and_the_Welfare_State_in_Spain.

7 Stimpson JP, Wilson FA, Eschbach K. Trends in health care spending for immigrants in the United States. Health Aff (Millwood) 2010:29:544-50.

8 Abu-Hayyeh R. Immigration Act 2014 and the slow dismantling of the NHS. 2015 Apr 23. www.irr.org.uk/news/immigration-act-2014-and-the-slow-dismantling-of-the-nhs/.

9 Swedish Agency for Public Management. Vård till papperslösa [Swedish]. 2015. www. statskontoret.se/globalassets/publikationer/2015/201510.pdf.

10 Platform for international cooperation on undocumented migrants. European patients forum calls for health care for all. PICUM Bulletin 2015 Apr 20. http://picum.org/en/news/ bulletins/46726/\#cat_25446.

Cite this as: BMJ 2015;350:h3056

\section{Related links thebmj.com}

- How much care is provided to migrants in different countries? See a related infographic online

(c) BMJ Publishing Group Ltd 2015 


\section{Figures}

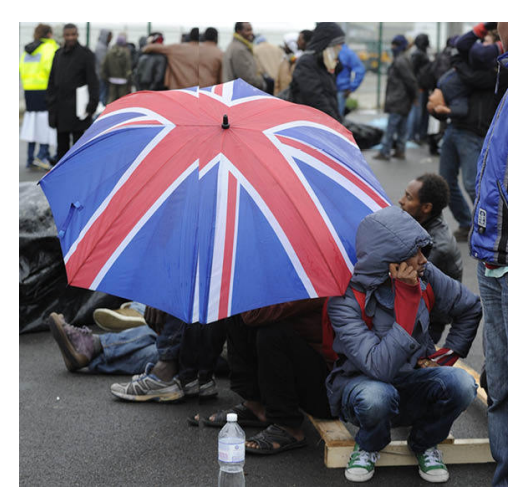

[Image: SARAH ALCALAY / DOCTORS OF THE WORLD]

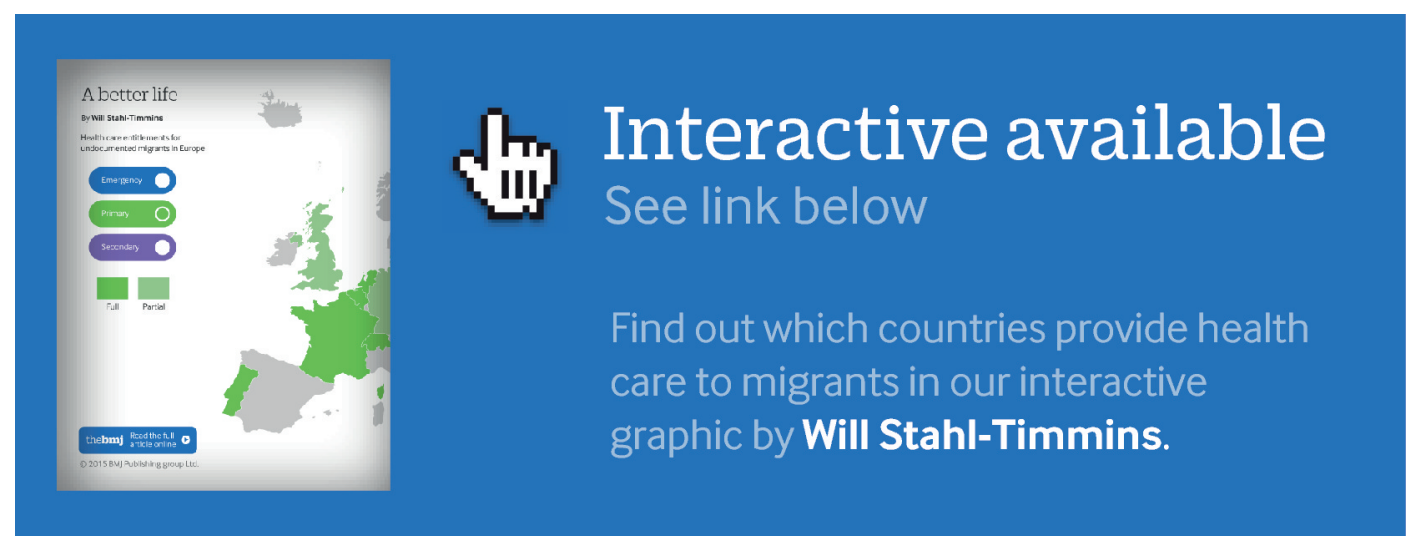

View interactive map at www.bmj.com/content/350/bmj.h3056/infographic 